\author{
Marek MOTYLEWICZ ${ }^{1}$ \\ Władysław GARDZIEJCZYK ${ }^{2}$
}

\title{
WPLYW CHARAKTERYSTYK RUCHU NA POZIOM HALASU W OTOCZENIU PRZYKŁADOWYCH SKRZYŻOWAŃ Z WYSPĄ CENTRALNĄ
}

\begin{abstract}
Skrzyżowania drogowe z uwagi na zróżnicowaną organizację i warunki ruchu samochodowego tworzą zdecydowanie bardziej złożoną sytuację pod względem oceny i prognozowania hałasu $\mathrm{w}$ ich otoczeniu $\mathrm{w}$ porównaniu $\mathrm{z}$ odcinkami międzywęzłowymi. Szczególnym przypadkiem w tym zakresie są skrzyżowania z wyspą centralną z sygnalizacją świetlną. Celem prowadzonych badań i analiz było określenie wpływu natężenia ruchu oraz struktury rodzajowej i struktury kierunkowej pojazdów na poziom hałasu w otoczeniu przykładowych skrzyżowań z wyspą centralną funkcjonujących na obszarze miasta Białystok. Analizie poddano wyniki 979 jednogodzinowych pomiarów równoważnego poziomu dźwięku $\mathrm{L}_{\text {Aeq }}$. Pomiary poziomu hałasu prowadzono na wysokości $1,50 \mathrm{~m}$ nad poziomem nawierzchni, w punktach zlokalizowanych pomiędzy „ramionami” skrzyżowania (promieniście względem jego środka), w odległościach $10 \mathrm{~m}$ i $20 \mathrm{~m}$ od krawędzi jezdni. Równolegle z pomiarami hałasu, na każdym wlocie skrzyżowania wykonywano pomiary natężenia, struktury kierunkowej i struktury rodzajowej ruchu pojazdów. Na podstawie uzyskanych wyników pomiarów ustalono zależności regresyjne pomiędzy równoważnym poziomem dźwięku a całkowitym natężeniem ruchu na każdym $\mathrm{z}$ analizowanych skrzyżowań. Na ich podstawie obliczono wartości $\mathrm{L}_{\mathrm{Aeq}} \mathrm{W}$ odległości $10 \mathrm{~m}$ i $20 \mathrm{~m}$ od krawędzi jezdni przy natężeniach ruchu na całym skrzyżowaniu: 3000, 3500, 4000 i $4500 \mathrm{P} / \mathrm{h}$. Na badanych skrzyżowaniach stwierdzono różnice pomiędzy wartościami $\mathrm{L}_{\text {Aeq }}$ na wlotach tego samego skrzyżowania do $2,5 \mathrm{~dB}$. Wpływ wartości tych różnic ma w szczególności udział tzw. pojazdów hałaśliwych i ich struktura kierunkowa. W artykule przedstawiono opracowane zależności funkcyjne pomiędzy równoważnym poziomem dźwię$\mathrm{ku}$ a charakterystykami ruchu samochodowego na badanych skrzyżowaniach.
\end{abstract}

Słowa kluczowe: równoważny poziom dźwięku, skrzyżowania z wyspą centralną, natężenie ruchu, pojazdy hałaśliwe

\section{Wprowadzenie}

Skrzyżowania drogowe charakteryzują się zupełnie odmiennymi warunkami ruchu $\mathrm{w}$ porównaniu z odcinkami międzywęzłowymi. Tworzą tym samym zdecydo-

\footnotetext{
${ }^{1}$ Autor do korespondencji/corresponding author: Marek Motylewicz, Politechnika Białostocka, ul. Wiejska 45E, 15-351 Białystok, +48 8574696 03, m.motylewicz@ pb.edu.pl

${ }^{2}$ Władysław Gardziejczyk, Politechnika Białostocka,w.gardziejczyk@pb.edu.pl
} 
wanie bardziej złożoną sytuację pod względem oceny i prognozowania hałasu w ich otoczeniu. Wyniki dotychczasowych prac badawczych dotyczących tego problemu $\mathrm{z}$ różną dokładnością odwzorowują rzeczywistą sytuację $[1,3,4,6,9,10]$. Większość $\mathrm{z}$ nich odnosi się do typowych rozwiązań w zakresie geometrii skrzyżowania z ewentualnym uwzględnieniem organizacji ruchu. W obowiązujących metodach brak jest szczegółowych informacji na temat prognozowania hałasu w otoczeniu bardziej rozbudowanych skrzyżowań skanalizowanych, jak np. ronda lub skrzyżowania z wyspą centralną. Podawane są wyłącznie szacunkowe różnice w odniesieniu do typowych skrzyżowań. Na przykład, w przypadku metody niemieckiej RLS-90 [8] i metody holenderskiej [2], dla skrzyżowań z sygnalizacją świetlną zaleca się wprowadzenie do obliczeń poprawki „K”, której wartość zależy od odległości odbiorcy dźwięku od skrzyżowania. W literaturze brak jest także informacji na temat prowadzonych szczegółowych badań terenowych hałasu w otoczeniu skrzyżowań.

W ostatnich latach w naszym kraju pojawia się coraz więcej skrzyżowań $\mathrm{z}$ wyspą centralną z sygnalizacją świetlną. Cechą charakterystyczną tego rozwiązania są wewnętrzne powierzchnie akumulacyjne dla pojazdów skręcających w lewo, powstałe wokół wyspy centralnej o średnicy od 30 do $60 \mathrm{~m}$. Pod względem organizacji ruchu są one porównywane do zespołu 4 skrzyżowań dwóch jednokierunkowych jezdni położonych na niewielkiej przestrzeni. Poprawne zaprojektowanie i skoordynowanie sygnalizacji świetlnej układu tych sub-skrzyżowań, z uwzględnieniem natężeń relacji skrętu w lewo, gwarantuje przepustowość od 4000 do 8500 $\mathrm{P} / \mathrm{h}[7,11]$. Z uwagi na geometrię oraz organizację ruchu skrzyżowań z wyspą centralną, prognozowanie hałasu $\mathrm{w}$ ich otoczeniu w oparciu o metody przeznaczone dla zwykłych skrzyżowań może prowadzić do znacznych błędów. Fakt ten może mieć istotny wpływ na planowanie oraz projektowanie zabezpieczeń przeciwhałasowych.

Celem prowadzonych badań i analiz jest określenie wpływu natężenia oraz struktury rodzajowej i struktury kierunkowej ruchu pojazdów na poziom hałasu $\mathrm{w}$ otoczeniu skrzyżowań $\mathrm{z}$ wyspą centralną. $\mathrm{W}$ artykule zaprezentowano wyniki tych analiz w odniesieniu do 3 skrzyżowań, a bardziej szczegółowe rozważania autorzy przedstawili w pracy [5].

\section{Program badań}

W ramach badań wykonano pomiary równoważnego poziomu dźwięku w otoczeniu 3 skrzyżowań z wyspą centralną położonych w Białymstoku, oznaczonych jako: W2, W5, W6 (zgodnie z oznaczeniami przyjętymi w [5, 7]). Równolegle ustalono natężenia ruchu wraz ze strukturą rodzajową i strukturą kierunkową ruchu pojazdów. W tabeli 1 przedstawiono ogólną charakterystykę analizowanych skrzyżowań wraz $\mathrm{z}$ danymi o ruchu pojazdów na wlotach $\left(\mathrm{Q}_{\mathrm{wl}}\right)$ i skrzyżowaniu $\left(\mathrm{Q}_{\mathrm{sk}}\right)$ w czasie pomiarów. Pojazdy ciężarowe, autobusy i motocykle zaliczono do tzw. pojazdów hałaśliwych i podano ich procentowy udział w całkowitym natężeniu ruchu na danym skrzyżowaniu $\left(\% \mathrm{PH}_{\mathrm{sk}}\right)$. Na rysunku 1 pokazano geometrię analizowanych skrzyżowań, lokalizację punktów pomiaru hałasu oraz strukturę kierunkową ruchu pojazdów hałaśliwych. 
Tabela 1. Charakterystyka analizowanych skrzyżowań z wyspą centralną

Table 1. Characteristics of the analysed signalized roundabouts

\begin{tabular}{|c|c|c|c|c|c|}
\hline Skrzyżowanie & $\begin{array}{c}\text { Średnica wyspy } \\
\text { centralnej, }[\mathbf{m}]\end{array}$ & $\begin{array}{c}\text { Liczba pasów } \\
\text { ruchu na wlotach }\end{array}$ & $\mathbf{Q}_{\text {sk. }}[\mathbf{P} / \mathbf{h}]$ & $\mathbf{Q}_{\text {wl. }}[\mathbf{P} / \mathbf{h}]$ & $\begin{array}{c}\mathbf{\% P H}_{\text {sk }} \\
{[\mathbf{\%}]}\end{array}$ \\
\hline W2 & 54,5 & 3 & $175-4944$ & $24-1600$ & $4,4-47,0$ \\
\hline W5 & 33,1 & 4 lub 5 & $214-4612$ & $37-1508$ & $2,0-10,5$ \\
\hline W6 & 34,5 & 4 & $133-3652$ & $12-1440$ & $3,3-23,3$ \\
\hline
\end{tabular}

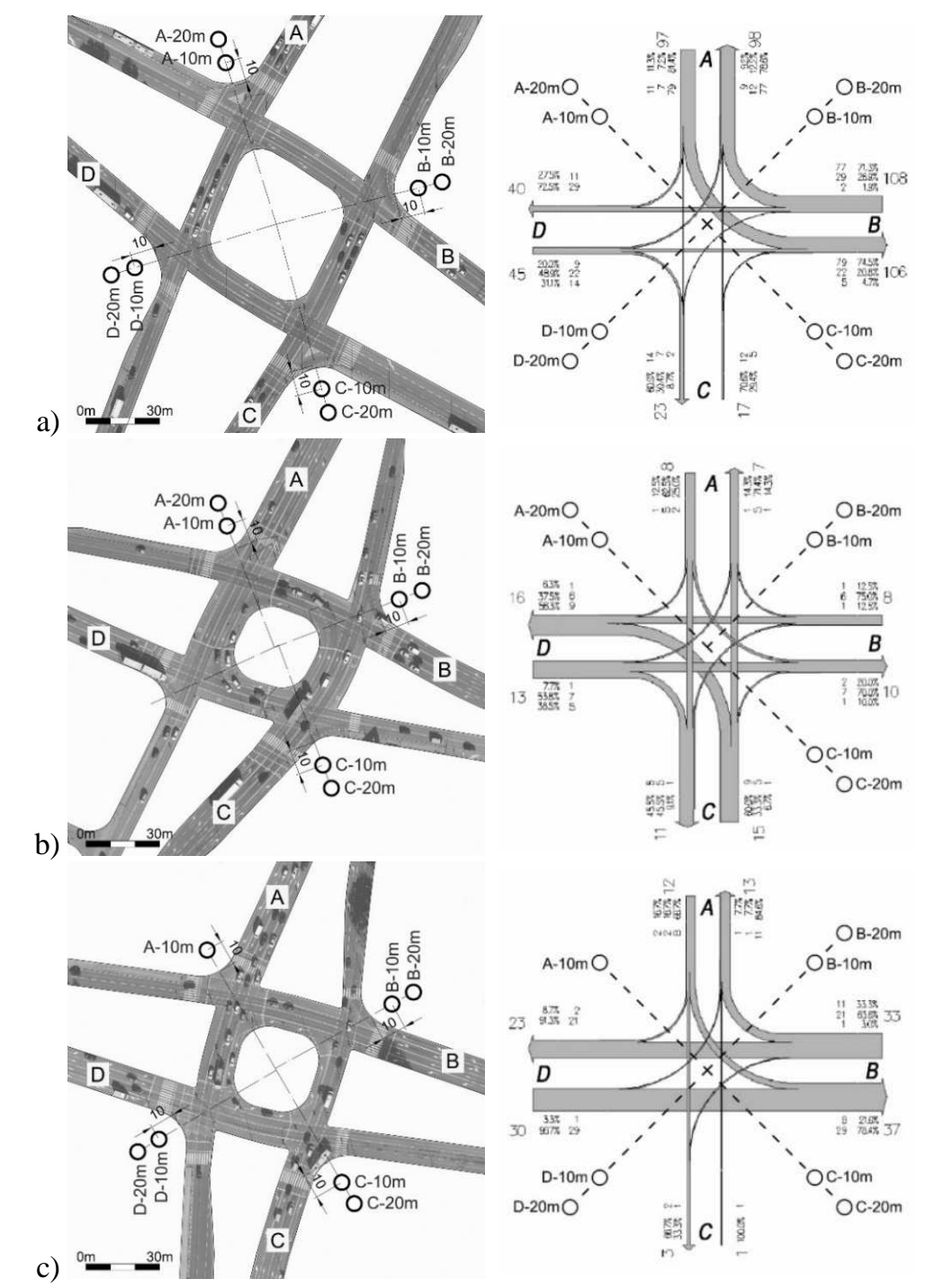

Rys. 1. Geometria skrzyżowań wraz z lokalizacją punktów pomiaru hałasu oraz rozkład ruchu pojazdów hałaśliwych dla przykładowej godziny pomiaru: a) W2, b) W5, c) W6 (A-D: wloty)

Fig. 1. Geometry of intersections with the location of noise level measurement points and the direction of noisy vehicles for a sample hour of measurement a) W2, b) W5, c) W6 (A-D: entries) 
Pomiary równoważnego poziomu dźwięku $\left(\mathrm{L}_{\text {Aeq }}\right)$ wykonano pięcioma cyfrowymi analizatorami dźwięku kl. 1, na wysokości $1,50 \mathrm{~m}$ nad poziomem nawierzchni, w różnych porach dnia. Punkty pomiarowe zlokalizowano pomiędzy „,ramionami” skrzyżowania (promieniście względem jego środka), w odległościach 10 i $20 \mathrm{~m}$ od krawędzi jezdni (rys. 1). Analizie poddano łącznie 979 jednogodzinowych wyników pomiarów (uzupełnionych w stosunku do pracy [5] o wyniki pomiarów z roku 2015). Z uwagi na zagospodarowanie otoczenia (zabudowa, ekrany akustyczne, tablice reklamowe, znaczne pochylenia terenu) na niektórych wlotach skrzyżowań nie było możliwym wykonanie pomiarów we wszystkich ustalonych odległościach.

\section{Wyniki pomiarów i ich analiza}

Wyniki pomiarów $\mathrm{L}_{\text {Aeq }} \mathrm{w}$ obrębie 4 wlotów (A, B, C i D) badanych skrzyżowań stanowiły podstawę do przeprowadzenia analizy wpływu charakterystyki ruchu pojazdów na klimat akustyczny w ich otoczeniu. Na rysunku 2, jako przy$\mathrm{kład,} \mathrm{pokazano} \mathrm{wartości} \mathrm{równoważnego} \mathrm{poziomu} \mathrm{dźwięku} \mathrm{L}_{\mathrm{Aeq}}$ uzyskane w otoczeniu skrzyżowania W2 w zależności od natężenia ruchu na całym skrzyżowaniu $\left(\mathrm{O}_{\mathrm{sk}}\right)$. Ustalone zależności regresyjne pomiędzy równoważnym poziomem dźwięku a całkowitym natężeniem ruchu na analizowanych skrzyżowaniach podano $\mathrm{w}$ tabeli 2 . Na ich podstawie obliczono wartości $\mathrm{L}_{\text {Aeq }} \mathrm{W}$ odległościach $10 \mathrm{~m}$ i $20 \mathrm{~m}$ od krawędzi jezdni przy natężeniu ruchu na całym skrzyżowaniu $\mathrm{Q}_{\mathrm{sk}}=3000 \mathrm{P} / \mathrm{h}, 3500 \mathrm{P} / \mathrm{h}, 4000 \mathrm{P} / \mathrm{h}$ i $4500 \mathrm{P} / \mathrm{h}$, a wyniki tych obliczeń przedstawiono w tabeli 3 .
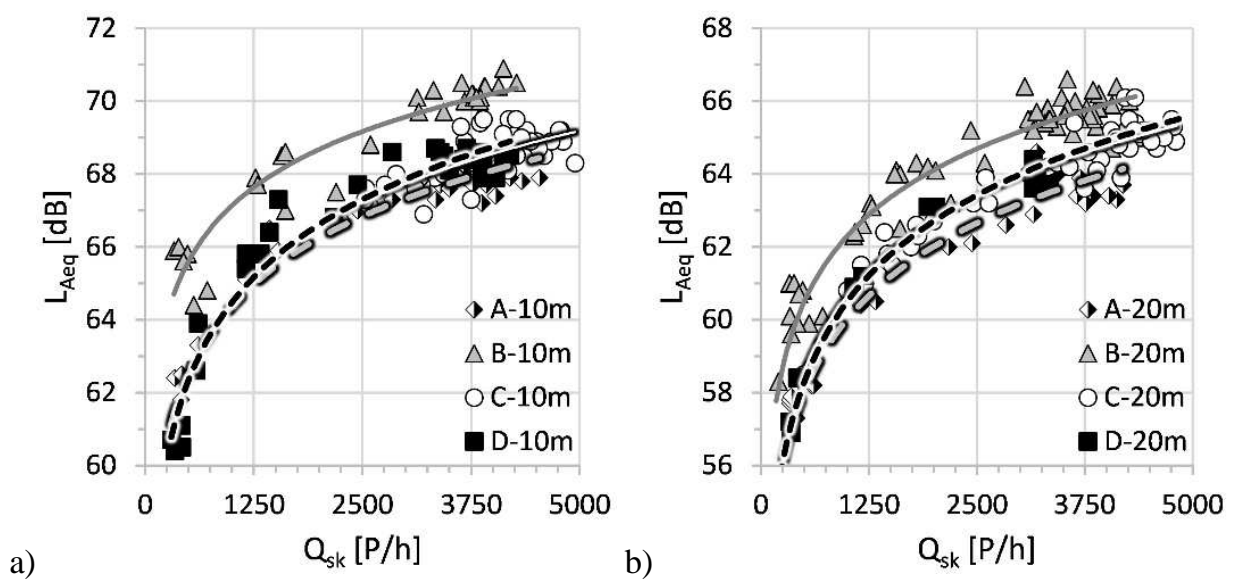

Rys. 2. $\mathrm{L}_{\text {Aeq }}$ w odległości $10 \mathrm{~m}$ (a) i $20 \mathrm{~m}$ (b) od krawędzi jezdni skrzyżowania W2

Fig. 2. $\mathrm{L}_{\text {Aeq }}$ at $10 \mathrm{~m}$ (a) and $20 \mathrm{~m}$ (b) from the edge of the intersection $\mathrm{W} 2$ 
Tabela 2. Zależności regresyjne pomiędzy wartością $\mathrm{L}_{\mathrm{Aeq}}$ a natężeniem ruchu pojazdów na całym skrzyżowaniu $\mathrm{Q}_{\mathrm{sk}}$

Table 2. Regressive relations between $\mathrm{L}_{\mathrm{Aeq}}$ value and traffic volume on the entire intersection $\mathrm{Q}_{\mathrm{sk}}$

\begin{tabular}{|c|c|c|c|c|c|}
\hline Punkt & Równanie & $\mathbf{R}^{\mathbf{2}}$ & Punkt & Równanie & $\mathbf{R}^{\mathbf{2}}$ \\
\hline \multicolumn{7}{|c|}{ skrzyżowanie W2 } \\
\hline A-10m & $\mathrm{y}=6,19 \cdot \log (\mathrm{x})+45,81$ & 0,93 & A-20m & $\mathrm{y}=6,61 \cdot \log (\mathrm{x})+40,17$ & 0,94 \\
\hline B-10m & $\mathrm{y}=5,09 \cdot \log (\mathrm{x})+51,86$ & 0,89 & $\mathrm{~B}-20 \mathrm{~m}$ & $\mathrm{y}=5,99 \cdot \log (\mathrm{x})+44,32$ & 0,93 \\
\hline C-10m & $\mathrm{y}=6,52 \cdot \log (\mathrm{x})+45,07$ & 0,56 & $\mathrm{C}-20 \mathrm{~m}$ & $\mathrm{y}=6,84 \cdot \log (\mathrm{x})+40,16$ & 0,92 \\
\hline D-10m & $\mathrm{y}=7,09 \cdot \log (\mathrm{x})+43,21$ & 0,95 & $\mathrm{D}-20 \mathrm{~m}$ & $\mathrm{y}=7,30 \cdot \log (\mathrm{x})+38,58$ & 0,99 \\
\hline \multicolumn{7}{|c|}{ skrzyżowanie W5 } \\
\hline A-10m & $\mathrm{y}=7,74 \cdot \log (\mathrm{x})+39,70$ & 0,95 & A-20m & $\mathrm{y}=6,82 \cdot \log (\mathrm{x})+39,53$ & 0,95 \\
\hline B-10m & $\mathrm{y}=7,46 \cdot \log (\mathrm{x})+39,38$ & 0,90 & B-20m & $\mathrm{y}=6,52 \cdot \log (\mathrm{x})+38,12$ & 0,93 \\
\hline C-10m & $\mathrm{y}=7,62 \cdot \log (\mathrm{x})+38,59$ & 0,95 & C-20m & $\mathrm{y}=6,61 \cdot \log (\mathrm{x})+37,94$ & 0,95 \\
\hline \multicolumn{7}{|c|}{ skrzyżowanie W6 } \\
\hline A-10m & $\mathrm{y}=6,52 \cdot \log (\mathrm{x})+44,68$ & 0,86 & A-20m & - & - \\
\hline B-10m & $\mathrm{y}=7,39 \cdot \log (\mathrm{x})+41,94$ & 0,86 & $\mathrm{~B}-20 \mathrm{~m}$ & $\mathrm{y}=7,09 \cdot \log (\mathrm{x})+39,53$ & 0,92 \\
\hline C-10m & $\mathrm{y}=5,66 \cdot \log (\mathrm{x})+46,89$ & 0,63 & $\mathrm{C}-20 \mathrm{~m}$ & $\mathrm{y}=5,71 \cdot \log (\mathrm{x})+42,91$ & 0,93 \\
\hline $\mathrm{D}-10 \mathrm{~m}$ & $\mathrm{y}=6,91 \cdot \log (\mathrm{x})+42,46$ & 0,87 & $\mathrm{D}-20 \mathrm{~m}$ & $\mathrm{y}=7,35 \cdot \log (\mathrm{x})+37,55$ & 0,95 \\
\hline
\end{tabular}

Analizę wyników podanych w tabeli 3 przeprowadzono z uwzględnieniem charakterystyki ruchu na skrzyżowaniach W2, W5 i W6. W otoczeniu skrzyżowań W5 i W6 uzyskano zbliżone wartości poziomu hałasu. Jest to wynikiem podobnej geometrii tych skrzyżowań oraz struktury rodzajowej ruchu. Na skrzyżowaniu W2, pomimo zdecydowanie większej średnicy wyspy centralnej niż na skrzyżowaniach W5 i W6, zanotowano wyższe poziomy dźwięku przy tej samej wartości natężenia ruchu $\mathrm{Q}_{\mathrm{sk}}$. Wpływ na taką sytuację ma zdecydowanie większy udział pojazdów ciężarowych w ruchu na skrzyżowaniu W2.

Tabela 3. Wartości $\mathrm{L}_{\mathrm{Aeq}}$ w otoczeniu wlotów skrzyżowań z wyspą centralną

Table 3. $\mathrm{L}_{\text {Aeq }}$ values in the vicinity of the signalized roundabouts' entries

\begin{tabular}{|c|c|c|c|c|c|c|c|c|c|c|c|c|}
\hline \multirow{3}{*}{$\begin{array}{c}\mathbf{Q}_{\text {sk }} \\
{[\mathbf{P} / \mathbf{h}]}\end{array}$} & \multirow{3}{*}{ Punkt } & \multicolumn{11}{|c|}{ Równoważny poziom dźwięku $\mathrm{L}_{\mathrm{Aeq}}[\mathrm{dB}]$} \\
\hline & & \multicolumn{4}{|c|}{ Skrzyżowanie W2 } & \multicolumn{3}{|c|}{ Skrzyżowanie W5 *) } & \multicolumn{4}{|c|}{ Skrzyżowanie W6 *) } \\
\hline & & $\mathbf{A}$ & B & $\mathbf{C}$ & D & $\mathbf{A}$ & B & $\mathbf{C}$ & $\mathbf{A}$ & B & $\mathbf{C}$ & D \\
\hline \multirow{2}{*}{3000} & $10 \mathrm{~m}$ & 67,3 & 69,6 & 67,7 & 67,9 & 66,6 & 65,3 & 65,1 & 67,3 & 67,6 & 66,6 & 66,5 \\
\hline & $20 \mathrm{~m}$ & 63,1 & 65,1 & 63,9 & 64,0 & 63,2 & 60,8 & 60,9 & - & 64,2 & 62,8 & 63,1 \\
\hline \multirow{2}{*}{3500} & $10 \mathrm{~m}$ & 67,8 & 69,9 & 68,2 & 68,3 & 67,1 & 65,8 & 65,6 & 67,8 & 68,1 & 67,0 & 66,9 \\
\hline & $20 \mathrm{~m}$ & 63,6 & 65,5 & 64,4 & 64,5 & 63,7 & 61,2 & 61,4 & - & 64,7 & 63,1 & 63,6 \\
\hline \multirow{2}{*}{4000} & $10 \mathrm{~m}$ & 68,1 & 70,2 & 68,5 & 68,8 & 67,6 & 66,3 & 66,0 & - & - & - & - \\
\hline & $20 \mathrm{~m}$ & 64,0 & 65,9 & 64,8 & 64,9 & 64,1 & 61,6 & 61,7 & - & - & - & - \\
\hline \multirow{2}{*}{4500} & $10 \mathrm{~m}$ & 68,4 & 70,5 & 68,9 & 69,1 & 68,0 & 66,6 & 66,4 & - & - & - & - \\
\hline & $20 \mathrm{~m}$ & 64,3 & 66,2 & 65,1 & 65,2 & 64,4 & 61,9 & 62,1 & - & - & - & - \\
\hline
\end{tabular}


Na skrzyżowaniu W2 największe różnice pomiędzy równoważnym poziomem dźwięku w odległości $10 \mathrm{~m}$ od krawędzi jezdni zanotowano pomiędzy wlotami B i A. Wynoszą one przy badanych natężeniach od 2,1 do 2,3 dB. Zbliżone różnice dla tych wlotów zanotowano również w punktach położonych w odległości $20 \mathrm{~m}$. Nie stwierdzono istotnych różnic pomiędzy poziomami hałasu w obrębie wlotów A, C i D w odległości $10 \mathrm{~m}$ od krawędzi jezdni. W odległości $20 \mathrm{~m}$ poziom hałasu w otoczeniu wlotu $\mathrm{C}$ był wyższy o około $0,8 \mathrm{~dB}$ niż w otoczeniu wlotów A i D. Przyczyną występowania tych różnic są stosunkowo duże natężenia tzw. pojazdów hałaśliwych skręcających w lewo z wlotu A oraz skręcających w prawo $\mathrm{z}$ wlotu B (rys. 1a). Zbliżanie lub oddalanie się źródeł hałasu od punktów pomiarowych zadecydowało o zanotowanych różnicach.

W przypadku skrzyżowania W5, w odległości $10 \mathrm{~m}$ i $20 \mathrm{~m}$ od krawędzi jezdni, różnice pomiędzy obliczonymi wartościami $\mathrm{L}_{\mathrm{Aeq}} \mathrm{W}$ obrębie wlotów $\mathrm{B}$ i C nie były znaczące. Jedynie w punkcie pomiarowym położonym w pobliżu wlotu A otrzymano wartości $\mathrm{L}_{\text {Aeq }}$ wyższe o około $1,5 \mathrm{~dB}$ w odległości $10 \mathrm{~m}$ od krawędzi jezdni oraz wyższe o około $2,5 \mathrm{~dB}$ w odległości $20 \mathrm{~m}$. Przyczyną takiej różnicy jest większy udział $\mathrm{w}$ ruchu tzw. pojazdów hałaśliwych na relacji $\mathrm{CL}$ (rys. 1b), wpływających na poziom hałasu w pobliżu wlotu A.

W otoczeniu skrzyżowania W6 różnice pomiędzy obliczonymi wartościami $\mathrm{L}_{\text {Aeq }} \mathrm{w}$ punktach położonych obok wlotów A i B oraz C i D wynoszą około $1,2 \mathrm{~dB}$ w odległości $10 \mathrm{~m}$ od krawędzi jezdni oraz 1,5 dB w odległości $20 \mathrm{~m}$. Pomimo zbliżonego natężenia ruchu pojazdów hałaśliwych na wlotach B i D (rys. 1c), duży ich udział na relacji skrętu w prawo na wlocie B powoduje większe wartości $\mathrm{L}_{\mathrm{Aeq}} \mathrm{W}$ punkcie pomiarowym położonym w pobliżu tego wlotu.

W oparciu o wyniki przeprowadzonych badań opracowano zależności funkcyjne pomiędzy równoważnym poziomem dźwięku w odległościach $10 \mathrm{~m}$ i $20 \mathrm{~m}$ od krawędzi jezdni a charakterystykami ruchu na skrzyżowaniu. Po wyeliminowaniu nieistotnych czynników i sprawdzeniu adekwatności modeli na poziomie istotności $\alpha=0.05$ zależności te przedstawiają się następująco:

$$
\begin{gathered}
\mathrm{L}_{\text {Aeq, } 10 \mathrm{~m}}=34,655+8,865 \cdot \log \mathrm{Q}_{\mathrm{sk}}+0,133 \cdot \% \mathrm{PH}_{\mathrm{sk}}+0,027 \cdot \% \mathrm{PH}_{\mathrm{wl}}+0,019 \cdot \% \mathrm{SP}_{\mathrm{PH}, \mathrm{wl}} \\
\mathrm{N}=551 ; \mathrm{R}^{2}=0,753 ; \mathrm{Se}=1,116 \\
\mathrm{~L}_{\text {Aeq, } 20 \mathrm{~m}}=33,550+7,977 \cdot \log \mathrm{Q}_{\mathrm{sk}}+0,111 \cdot \% \mathrm{PH}_{\mathrm{sk}}+0,039 \cdot \% \mathrm{PH}_{\mathrm{wl}}+0,020 \cdot \% \mathrm{SP}_{\mathrm{PH}, \mathrm{wl}} \\
\mathrm{N}=428 ; \mathrm{R}^{2}=0,826 ; \mathrm{Se}=1,218
\end{gathered}
$$

gdzie: $\mathrm{Q}_{\text {sk }}$ - natężenie ruchu pojazdów na całym skrzyżowaniu, $[\mathrm{P} / \mathrm{h}]$

$\% \mathrm{PH}_{\mathrm{sk}} / \mathrm{wl}-$ udział pojazdów hałaśliwych $\mathrm{w}$ ruchu na skrzyżowaniu / wlocie [\%],

$\% \mathrm{SP}_{\mathrm{PH}, \mathrm{wl}}$ - procentowy udział pojazdów hałaśliwych skręcających w prawo w łącznym natężeniu ruchu tych pojazdów na wlocie, [\%]. 
Opracowane zależności wskazują na istotny wpływ natężenia pojazdów ogółem oraz tzw. pojazdów hałaśliwych na skrzyżowaniu na klimat akustyczny w jego otoczeniu. Poziom hałasu w obrębie poszczególnych wlotów jest uzależniony także od udziału pojazdów ciężarowych, autobusów i motocykli w ruchu na tym wlocie oraz pojazdów hałaśliwych skręcających z tego wlotu w prawo.

\section{Wnioski}

Ocena i prognozowanie klimatu akustycznego w otoczeniu skrzyżowań jest zagadnieniem zdecydowanie bardziej złożonym niż w otoczeniu odcinków międzywęzłowych. W grupie skrzyżowań nieco innego podejścia wymagają skrzyżowania $\mathrm{z}$ wyspą centralną, traktowane $\mathrm{w}$ obliczeniach przepustowości jako niezależne skrzyżowania jednokierunkowych jezdni położone na niewielkiej powierzchni. Wyniki badań i analiz wykazały, że przy zbliżonych natężeniach ruchu istotny wpływ na hałas w ich otoczeniu ma udział tzw. pojazdów hałaśliwych (pojazdy ciężarowe, autobusy i motocykle). Na badanych skrzyżowaniach ustalono różnice pomiędzy poziomami dźwięku w otoczeniu poszczególnych wlotów o wartości do $2,5 \mathrm{~dB}$. Jest to wynikiem różnic w natężeniach, strukturze kierunkowej i rodzajowej ruchu pojazdów na wlotach skrzyżowań. Opracowane zależności funkcyjne wskazały także na istotny wpływ ruchu pojazdów hałaśliwych na wlocie skrzyżowania (ogółem i skręcających w prawo).

\section{Literatura}

[1] Abo-Qudais S., Alhiary, A.: Statistical models for traffic noise at signalized intersections. Building and Environment, 42, 2007, s. 2939-2948.

[2] ASVV. Aanbevelingen voor verkeersvoorzieningen binnen de bebouwde kom. CROW, 1989.

[3] Bohatkiewicz J.: Badania czynników powodujących zwiększenie poziomu hałasu w otoczeniu skrzyżowań drogowych, w: Ochrona środowiska i estetyka w drogownictwie. SITK RP, Lublin 2000, s. 199-210.

[4] Chevallier, E., Can, A., Nadji, M., Leclercq, L.: Improving noise assessment at intersections by modeling traffic dynamics. Transportation Research Part D, 14 (2009), s. $100-110$.

[5] Gardziejczyk W., Motylewicz M.: Noise level in the vicinity of signalized roundabouts. Transportation Research Part D, 46 (2016), s. 128-144.

[6] Makarewicz, R., Golebiewski, R.: Modeling of roundabout noise impact. Journal of the Acoustical Society of America, 122, 2007, s. 860-868.

[7] Motylewicz M., Gardziejczyk W.: Badanie i ocena warunków ruchu na skrzyżowaniach z wyspą centralną na przykładzie Białegostoku. Transport Miejski i Regionalny, 10, 2012, s. 8-15.

[8] RLS-90. Richtlinien für den Lärmschutz an Strassen, BM für Verkehr, Bonn, 1990.

[9] Samuels S., Sheperd R.: Prediction of traffic noise at simple, signalised intersections. Australian Road Research Board. Technical manual ATM No. 27, 1989. 
[10] Tracz M. Bohatkiewicz J. Effects of traffic conditions on traffic noise at signalized inter-section. Euro-Noise'95, Vol. 1, Lyon, 1995.

[11] Tracz M., Chodur J. Performance and Safety of Roundabouts with Traffic Signals. Procedia - Social and Behavioral Sciences, 53, 2012, s. 789-800.

\section{THE INFLUENCE OF TRAFFIC CHARACTERISTICS ON NOISE LEVEL IN THE VICINITY OF SAMPLE SIGNALIZED ROUNDABOUTS}

\section{S u m m a r y}

Road intersections are a more complex issue in the terms of noise level prediction and assessment in their vicinity than usual road sections, chiefly due to the varied traffic organisation and conditions. A unique case in this group is the signalized roundabout. The aim of the conducted research and analyses was to determine the influence of traffic volume and the type and direction of vehicles on the noise levels in the vicinity of sample signalized roundabouts in the area of Bialystok city. A total of 979 one-hour equivalent sound level measurements were analysed. The measurements were conducted at $1.50 \mathrm{~m}$ above street level, in points located between the 'arms' of the intersections (radiating from its centre), at distances of $10 \mathrm{~m}$ and $20 \mathrm{~m}$ from the edge of the road. Together with sound level measurements, traffic volume, direction and vehicle types measurements were conducted at each entry of the intersections. Based on the obtained results, regressive dependencies have been established between the equivalent sound level and total traffic volume at each of the analysed intersections. Based on this, the $\mathrm{L}_{\text {Aeq }}$ values have been calculated at a distance of $10 \mathrm{~m}$ and $20 \mathrm{~m}$ from the edge of the road, with traffic volumes on the intersections being: $3000,3500,4000$ and $4500 \mathrm{veh} / \mathrm{h}$. The analysed intersections also showed variations between the $\mathrm{L}_{\text {Aeq }}$ levels at the entries of up to $2.5 \mathrm{~dB}$. Such differences are especially influenced by the percentage of noisy vehicles and their direction. The article gives function dependencies between the equivalent sound level and the traffic characteristic at the analysed intersections.

Keywords: equivalent sound level, signalized roundabouts, traffic volume, noisy vehicles

Przestano do redakcji: 07.06.2016 r.

Przyjęto do druku: 30.06.2016 r.

DOI: $10.7862 / \mathrm{rb} .2016 .85$ 